\title{
Representation of Female Superhero and Gender Roles in the Avengers: Endgame
}

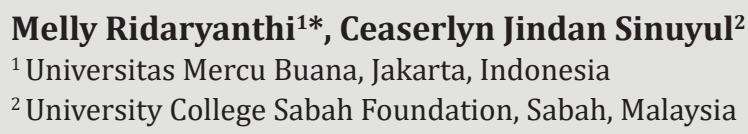

Article Information

Submitted February 24, 2021

Revised July 12, 2021

Accepted August 16, 2021

Published October 01, 2021

\begin{abstract}
This paper aims to present the study about the representation of female superhero characters and gender roles in Avenger: Endgame. This study is justified to be important as females usually have their stereotypical representation in mass media, including film. Thus, it is crucial to explore and analyze whether or not female superheroes are depicted similarly. There are three main characters analyzed in this movie, namely Gamora, Black Widow, and Nebula. This study applies the semiotics method with a qualitative approach whereby Roland Barthes Semiotics is employed as the theoretical foundation of the analysis and strategy in this study. The research has focused on the representation of gender roles and physical manifestations of the characters in the film. The study has shown that (i) each of the characters plays several roles based on the context of the story, (ii) the balance of power between male and female are not equally distributed, and lastly (iii) Gamora and Nebula being different species than Black Widow which is human, had their appearance interpreted to possess a human-like body, yet the pattern of body size among these three-female superheroes sends a message that this body shape is the "ideal and desirable" body type.
\end{abstract}

Keywords: Representation, Female Superhero, Stereotype, Semiotics, Film, Gender Roles

\section{Introduction}

The comic book is one of the American popular cultures, and it has long been entertaining its readership to the world of fictional characters in an alternate reality since 1897 (Gina Misiroglu, 2018). The history of comic book advancement and commercial success has been defined by several "ages": the Golden Age (1938-54), the Silver Age (1956-69), the Bronze Age (197080), the Late Bronze Age (1980-84), and the Modern Age (1985-present) through which the representation often reflect the year of when the comic was published and has been shifted as the year goes by, for example, Murphy (2014) stated that World War 2 timeline plays a significant role in comic book narrative, especially how female is being portrayed. During World War 2, the female's position, to be more than homemakers as the larger population of males enlisted to fight in the war. The authors tried to encourage females to become part of the war effort, to leave their homes, enter the workforce, and fill the jobs previously held by a male. This decade was the Golden Age of Comics when female superheroes were christened symbols of American strength, freedom, patriotism,

\footnotetext{
*Author Correspondence: Melly Ridaryanthi, melly@merubuana.ac.id, Mercu Buana University, Jl. Meruya Selatan No. 1 Kembangan, Jakarta 11650
}

Copyright (C) 2021 Melly Ridaryanthi, Ceaserlyn Jindan Sinuyul 
and independence (Larew, 1997).

However, it was short-lived as the roles revert to traditional family values where females began to retrieve back into the domestic sphere as males started to take over the workforce, and so did the comic books. First, they were treated as powerless sidekicks to their male counterparts. Then, they began disappearing altogether. As women were forced out of the public sphere, they also vanished from comics (Larew, 1997: 596). Comic books often represent the expression of thoughts and interpretation of the writer's point of view whereby consumed by the readers. According to Fisher (2013), writers often overlook the female perspective since the male storyline is considered dominant or universal. Hence, female representations in comic book storylines are stereotypical representations despite having equally powerful superpowers and are often in hyper-sexualized costumes or figures or framed into domestic roles such as sidekicks, the girlfriend, mother, or wife.

Among them, all is the most famous comic book to date is Marvel Comics. Marvel Comics first published "Marvel Comics \#1" in 1939, which included "Human Torch", "Angel" and "Prince Namor the Sub-Mariner". In the first year of Marvel Comics, female superheroes were outnumbered by male superheroes, not until November 1961 where "Invisible Girl A.K.A Susan Storm" debuted as the first female superhero. However, the invisibility power given to Susan Storm reflects how the writer limits her participation in the head-on combats, emphasizes more towards supporting her male teammates, and eventually became the romantic interest of the storyline. This fact provides an insight into how a female is being treated stereotypically.
As writers and customers, men are influential in the comic book industry and have been since the advent of mainstream comics such as D.C. and Marvel. For over the years, female comic book characters with inaccurate portrayals of women have been published, characterized to demonstrate the views of men on women, and eventually attracted to a heteronormative male audience as sex objects (Turberville, 2016).

Furthermore, Turberville (2016), in the study regarding misinterpretations of women in comic books, which interesting to relate before we jump into the film. Most of the portrayal of women is somehow misleading, or the interpretation is wrong. The character is considered more menial than the male hero. One of the participants in the study stated that gender roles in comics often follow the stereotype that gender roles are depicted as leaving women submissive and passive and forcing them at all times to have a sex appeal. This comment is interesting and important to be explored further as a comic story or film. Thus, the representations are depicted more visually, which may (or may not) perpetuate the existed stereotype.

However, in recent years, the film industry went into a trending binge of adopting superhero comic books into films, in this case, Marvel Cinematic Universe (MCU). MCU produced the highest-grossing film of all time, such as The Avengers, Avengers, Age of Ultron, Avengers: Infinity War, and the latest, The Avengers: End Game which was released in 2019. The continuous production of Marvel characters from comics into movies has given stereotype portrayal a new platform whereby the audience is exposed visually and audibly.

The study of gender role stereotypes in media has been a general area of psychology, 
sociology, and communication (Krahn, 2015). Female characters in films have been portrayed in various representations. The analysis of gender stereotypes in media is still relevant to be carried out nowadays to update the current portrayal and perception of the audience towards it. Media plays a significant role in influencing how society, in this case, the media audience, views the "reality" related to gender roles (Alzahrani, 2016).

Hall (2013) explained that representation is an essential part of how meaning is produced and exchanged between members of the culture. To interpret this world meaningfully, we often give values, depiction, or description towards any object, person, or social group, enabling us to refer to things both inside and out. Representation involves using language, signs, and Figures that depict or represent objects (Hall, 1997). Representation is neither as transparent nor straightforward a practice as it first appears. To unpack the idea, we need to work on a range of examples and bring to bear certain concepts and theories to explore and clarify its complexities (Hall, 1997). It is an essential part of a process how to produces, exchange, and shares meaning.

There are two systems or processes of representation. First, mental or conceptual representation is a concept about 'something' we carry around in our head (conceptual map). This representation is related to something considered abstract. The second system of representation is language. The abstract concept in our head should be translated into prevalent language used to relate concepts and ideas with certain symbols to understand (Eriyanto, 2001).

Hall (2013) suggested that there are two processes involved in the system of representation. He explained that the first system forms concepts or mental depictions of things we can perceive. The second system is how these concepts are translated into the common language to correlate the concepts to certain written words, spoken sounds, or visual images.

The previous paragraph on how we try to make sense of this world unconsciously leads to stereotype representation. Pickering (2016) explained stereotype is an unequal social relation, hard-and-fast definitions of others that diminish their social standing or render them as in some way inferior. The stereotype is an ideology or sets of belief towards gender, people of colour, religion, body image, and differently able people and are often negative, misleading, distorted, or exaggerated. Hence, it can be easily interpreted as reality. Continuation of stereotypes can lead to discrimination and further construction of false reality, for example, how female characteristics associate with dependence, indecision, and emotional, which consequently contributed to how females are treated in the workforce. However, these stereotypes do not represent females as a whole. Therefore, bring us to the question of how media play an essential role in perpetuating these stereotypes.

Every day we expose ourselves to various types of mass media, and it has become part of our life in which we utilize it in any situation possible. Be it in classrooms, in the waiting area, after school or work, and even while preparing dinner. These forms of media can be written, spoken, printed, or broadcast, communicated to a larger audience through television, radio, newspapers, the internet, films, and comic books. Although these communications are informative, 
entertaining, and educational nevertheless, representation is there.

Accordingto Baran (2014), representation contains meaning that often goes into a symbolic process whereby reality is produced, maintained, repaired, and transformed. This statement means media companies select, frame, and construct messages in such a way; it imitates real-life from a one-dimensional perspective, giving the audience relatable content. However, these types of content usually lead to stereotypical representation of any race, ethnicity, gender, and social class. Therefore, these representations can easily be interpreted as false reality if one exposes it repeatedly, fits into preferred categories, and eventually shapes the audience's perceptions. The media acknowledges these red flags; however, media could not seem to turn their backs on stereotypes, and it continues from one platform to another.

Furthermore, the lack of people from diverse cultural groups working within the media industry is the third reason why stereotypes continue to thrive. Lots of contents are made based on mere assumption, which brings us to the fourth reason: those who work in the media presume audiences will only accept specific images of a diverse group member. Lastly, due to these presumptions towards the audience, cultural practice predetermines what is worthy of coverage. However, stereotypes not only fall on cultural groups but onto gender as well, especially how females are portrayed stereotypically in media.

The difference between sex and gender is that sex is determined by the biological feature of an individual compared to gender. In contrast, gender is constructed by social and cultural for example, femininity and masculinity (Blackston, 2003). The continuation of female representation in media distorts the line between sex and gender by portraying female roles stereotypically and sexualized. The visual-centric media such as films, television programs, magazines, newspapers, and comic books will further constricting females from breaking out from this bubble that media has to enforce to the society.

Briandana and Hajariah (2013) stated, based on their study, that representation of gender and body in action film has shown that female action heroes have not simply given up their femininity in favour of masculine performance. They have been seen as transgressive in blurring the boundaries within the rigid notion of the gender binary. This argument is fascinating and challenges this study. It is trying to explore and comprehensively analyze the role and portrayal of females in the second order of meaning based on their representation in the film.

Basarah (2019), in her work on feminism representation in a web series "Sore-Istri Dari Masa Depan (Sore-A Wife from the future)", argued that Sore, a female character, managed herself to control her husband's life, Jo. Basrah claimed that the intention to control Jo's life represents a woman's life as well as domination for the sake of better future circumstances for their family. This paper has shown relevancy in the analysis with regards to gender role representation.

Historically, in post-war time, advertisements framed women into the domestic role to sell their product, such as Campbell's 1950's advertised their soup by headlining its poster "Clever Wife". This advertising shows a female standing over the 
stove whilst her husband stands behind her. This poster is indicating the female role as a housewife and a mother. The sexual image in films such as "The Asphalt Jungle" how Marilyn Monroe wears curvaceous dresses and had an alluring demeanour, platforming an "ideal" image of how females should look in real life.

In each passing year, media shapeshift the representation of females. The recent popularity of strong female heroines such as Katniss Everdeen in the Hunger Games series and Tris in the Divergent series may give the impression that women are often represented equally and relatively in films (Murphy J. N., 2015). In his 2002 book Media, Gender and Identity, David Gauntlett said that "the traditional views of a woman as a housewife or low-status worker has been kick-boxed out of the Figure by the feisty, successful 'girl power' icons" (p. 247). However, despite the recent "girl power" uprising trend in the film industry, the concern is that stereotype hides behind this term "girl power", thus making it harder to be identified as time evolves. A critic stated that the Hunger Games series ends with Katniss having surrendered all of her power to give Peeta the domestic life he desires. Yet, she is the more influential figure in their relationship, even if she chooses to suppress that power and serve her husband (Thaller, 2016). Hence, the importance of continuing to study the implication in the film is to unframed female representation and reshape how society's perceptions towards a female.

Majhi (2017), in the study entitled Gender Equality in Hollywood Superhero Movies, found that women's appearance in the lead roles seems to be the initiation of diminishing the misrepresentation of the existence of stereotypical gender roles. Most of the movie's storyline always takes the protagonist actress has to yield to the dominance of patriarchal social order as a closing scene of the film.

The study conducted by Murphy (2016) on analyzing female gender roles in Marvel Comics hypothesize that female gender roles in Marvel Comics in the last decade have become less stereotypical and more equitable compared to the 1960s. In her research, she chose to quantify her findings using a sevenpoint rubric whereby it underwent an interrater reliability test twice with ten experienced raters. The researcher reviewed 68 Marvel titles for 788 Marvel comic books broken down by decade from 1960 to 2014. The result was that female gender role stereotypes are still apparent and not close to equitable despite decades. By exploring Marvel's Comic newer platform, we can identify whether the female gender role representation in comics has been reconstructed or remained the same. The platform has shifted to a more extensive entertainment production.

From the deliberation of literature and related reading texts towards this study, it is essential to construct a conceptual definition that limits the scope of focus in the analysis and discussion of this study. Thus, the following are concepts applied in this study to focus:

1 Female superheroes-Female with superpower ability beyond human capabilities such as Black Widow, Captain Marvel, and Nebula. Nebula (Luphomoid species) define as female Nebula's biological features are similar to female human parts such as her chest, her slightly high pitch voice, and how Nebula's referred to by her peers as 'she', 'her', 'woman', or 'daughter' in both comic 
and film (Anthony Russo, 2019).

2 Representation is an essential part of how meaning is produced and exchanged between a cultured member (Hall, 2013). This study analyzes the representation of gender roles and sexualization in terms of body representation.

3 Sexualization - a person is sexually objectified - that is, made into a thing for others' sexual use, rather than seen as a person with the capacity for independent action and decision making; and/o (Zurbriggen, Collins, \& Lamb, 2007).

4 Gender Role - Gender roles are based on the different expectations that individuals, groups, and societies have of individuals based on their sex and each society's values and beliefs about gender (Blackston, 2003). This study explains gender roles covering occupation and balance of power.

From the study background explained, we can see that stereotype portrayal by the producers, in this case, Marvel Comics, has not stopped only in comics as the platform. The audience absorbs the narrative of the storyline and audiovisual as an attractive form of message. Finding an equal representation of females as heroes in comic books is challenging because their character is representation from one- dimensional perspective. A similar construction also shows in adaption films from Marvel comic books. Gerard (2018), in his work, stated that it is necessary to examine the representation of female characters in the MCU due to the reach of this franchise.

Furthermore, Avenger is a popular superhero movie with several sequels whereby female superheroes are continuously represented based on their roles in the group of superheroes. Therefore, analyzing the representation of their role, especially in the final sequel, is essential to highlight whether or not there is a reconstruction on the existed stereotype of female role representation. Based on the explanation above, this study analyses the representation of female superheroes in the Avenger: Endgame film by questioning the representation of female roles and physically depicted in the movie. This study is justified to be important as females usually have their stereotypical representation in mass media, including film. Thus, it is crucial to explore and analyze whether or not female superheroes are depicted similarly.

\section{Method}

The constructive paradigm in this research is using a qualitative approach. The semiotics method was employed to analyze the analysis unit in this study based on Roland Barthes Semiotics. The Barthes semiotics framework contains two meaning construction, that is, denotative and connotative sign. The concept of connotative is the critical key that distinguishes Barthes semiotics from the rest. Connotative refers to the second order of illustrates the interaction of readers' emotions and values of their culture (Wibowo, 2011).

In semiotics, denotation and connotation define the relationship between signifier and signified. Denotation is the first order of signification contains a signifier and a signified. However, connotation refers to the second order of denotative signs as its signifier, which relates to the additional signified. Thus, this makes denotation the primary meaning of the sign. 


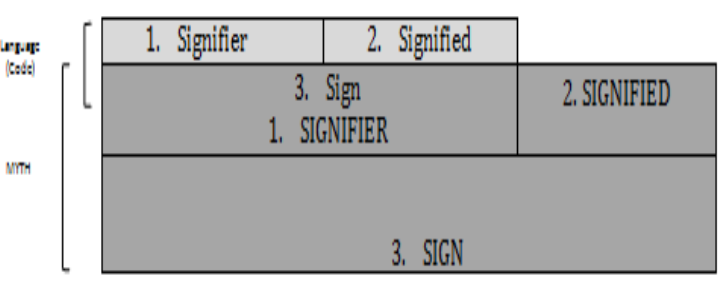

Figure 1. The concept of semiology proposed by Roland Barthes

The above figure represents Barthes Semiology, whereby meaning takes place in two stages of signification. Barthes semiology is composed of two levels of language system; the first level, language as the object, and the second level, known as the meta language. Based on this theory, the first sign system is the denotation, while the second is a connotation or mythological system.

According to Barthes, as cited in Bouzida (2014), to illustrate how meaning is generated by complex semiotic interaction, the image is connected to the esthetic and ideological influences that are open to readings and interpretations connotative degree. A wide range of texts, including photographs, ads, and films, are used, especially in media studies, to provide recipients with the information they need to interpret and create meaningful texts and designs. Roland Barthes's approach is highly applied in media studies that focus on the semiological analysis of such diverse media domains as advertising, video clips, caricature, or even films. Barthes brought up concepts of connotative and denotative as the critical analysis (Wibowo, 2011).

Analysis units are defined based on the focus of this study which are parts of the film that represent the female stereotype. The characters' complexities in the film have brought this research to categorize analysis units based on their gender role and sexualization, or physical, portrayal.
Semiotics as a method is a study of synchronic and diachronic signs. Morris, as cited in Danesi (2004), stated that the semiotics method could be divided into three focuses, i.e. (i) study about the relationship between a sign with the other signs, namely syntactic, (ii) study about the relationships among signs and its primary meaning, namely semantic, and lastly (iii) study about the relationship between signs and the users, namely pragmatic. Semiotics concerns more about the meaning of the message and how the message is delivered through signs. Thus, semiotics is employed to understand and analyze imaginary, confusing, and manipulative signs and messages (Danesi, 2004).

In this study, Barthes' semiotics is applied as a theory and method to guide to analysis of the units defined. The following table represents the categorization of the analysis unit used in the present study:

Table 1. Unit of Analysis

\begin{tabular}{|c|c|}
\hline Characters & Criterion for analysis \\
\hline Gamora & \multirow{5}{*}{$\begin{array}{l}\text { i. Gender role } \\
\text { a. Occupation } \\
\text { b. Balance of power } \\
\text { ii. Sexualization/physical } \\
\text { a. Body and outfit } \\
\text { representations }\end{array}$} \\
\hline Black Widow & \\
\hline Nebula & \\
\hline & \\
\hline & \\
\hline
\end{tabular}

The exploration of the unit analysis throughout the film is based on the criterion defined. Observation towards the unit analysis is the technique for data selection for analysis purposes. Barthes semiology is using to guide the analysis process. Two orders of signification are applied in the analysis process to interpret and analyze each analysis unit comprehensively base on its first and second order of importance. This study discusses the 
denotative meanings and further elaboration towards connotative meanings.

\section{Result and Discussion}

The result will be presented based on the description of each character defined as analysis units. Presentation of the results will be followed by the analysis and discussion based on the analysis criterion stated in the previous section.

Description of the Female Characters

She is the only Zen-Whoberis who were excluded from Thanos execu-
Characters
tion of her entire species, which then Thanos adopted her as his daughter.
Despite having a tragic past, the only person she cares for is her adoptive
sister Nebula, Although they have a love and hate relationship with each
other.
Gamora has superhuman strength and agility and an accelerated heal-
ing factor; however, she remained loyal, respected, and often obedient to
any Thanos's instruction despite not agreeing to any of Thanos's decisions.
She is also in constant competition with Nebula for approval and attention
from Thanos, their adoptive father figure.
Gamora is a non-human species called Zen-Whoberis species. However,
her figure resembles a human figure. She has a slender figure, arms, legs,
curvy waist, medium breast and no muscle profile on her body. Her facial
feature has an oval-shaped face, a set of thick eyelashes, and long mid-
length wavy hair. For her outfit, she wears a leathery, body-fitted material
and has an exposed chest to accentuate her cleavage.

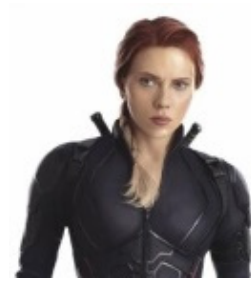

Black Widow

Five years since Thanos wiped half of the human population, Black Widow has been monitoring Hawkeye activities due to her feeling responsible for caring for him after his wife and children were wiped by Thanos. She considers the Avenger as her family and that they helped her become a better person.

She is mastering the covert arts of espionage, infiltration \& subterfuge. She is also a martial arts expert with exceptional agility \& athletic ability. Black Widow and Nebula are the only remaining female among six other male superheroes in the Avenger Headquarters.

During the discussion, she rarely intervened or had any opinion but only served as the voice of reason amongst her Avengers members whereby any decisions were made, and she will take notes of any mission or support any ideas they suggested. In addition, she sacrificed herself for the stone during her and Hawkeye time in Vormir to retrieve the soul stone. Her reasons are that Hawkeye life has value, for he has a family to go back to compare to her situation whereby she has no family or love interest.

Black Widow, also known as Natasha Romanoff, is a human with extraordinary martial art and agility skills. Her facial feature a diamond-shaped face with a high cheekbone. Like Gamora, she has a slender figure, arms and legs. However, there is a difference between when she puts on her combat suit and her everyday clothes. Her combat suit made her look slightly muscular, especially her upper torso; for her everyday clothes, she looks slender and has no muscle profile on her arms. 


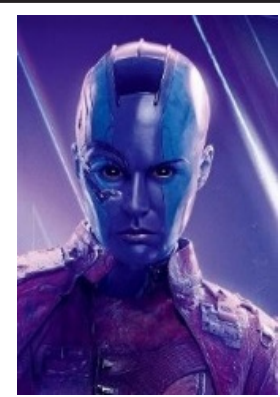

Nebula

Nebula is the adoptive daughter to Thanos and adoptive sister to Gamora. In the film, Nebula is seen as a daughter desperately in need of Thanos's approval and attention. She also cares for her sister, Gamora. Nebula is in a constant battle to gain Thanos approval and attention with Gamora. This battle can be seen through how she speaks highly of her father and behave respectfully around Thanos despite Thanos favouring Gamora more over her.

Meanwhile, in Avenger Headquarters, her role in preparing for the time travel mission, she can be seen assisting her male superheroes in configuring their suit. Nebula is Luphomoid species with semi-mechanical facial features with big round eyes. However, like Gamora, her body resembles human-like with slender sets of arms and legs, a set of breasts, and no muscle profile on her body, only when she puts on the jacket that made her look muscular. Her outfit is leathery, and body fitted material accentuates her figure further.

\section{Gender Role Representations}

a. Occupation

Regarding occupation in superheroes, it discourses how female status is portrayed, despite having superpowers or advanced ability to combat. This study can identify that three of the selected characters, Black Widow, Gamora, and Nebula, have domesticoccupation attached to their character throughout the film. This domestic role, considered as occupation, can be further explored as to how female's role stereotypically constructed in the society (refer to Figure 1). This understanding draws upon the previous study conducted by Arofat (2013) regarding females in the domestic realm. From several films included in the study, Arafat found that females, mostly portrayed as mothers or wives, are placed in domestic areas and do domestic tasks.

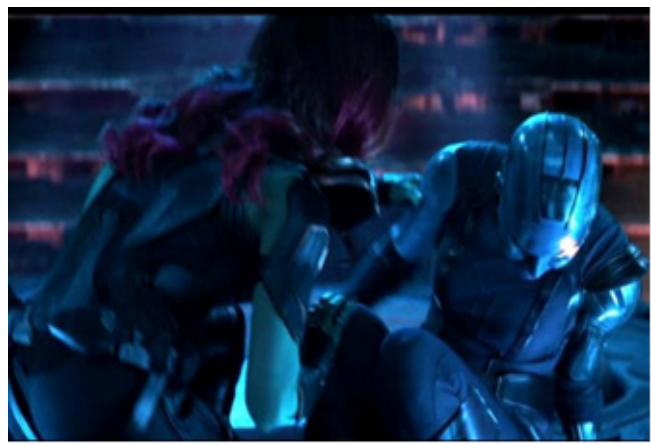

Figure 1 Women character in action
Gamora is seen as strong and expert in combat; however, her narrative gave insight into her role in the film as an adoptive daughter to Thanos after he massacred her entire species and an adoptive sister to Nebula. Gamora possesses a protective role as Nebula sister, which can be seen in the film till 1 hour 15 minutes whereby Gamora quickly rushed to Nebula side when her brain malfunction as it was connecting to the time-travelling Nebula and stood in between Nebula and Thanos, then tries to justify Nebula sudden brain malfunction to avoid Thanos wrath, refer to Figure 2.

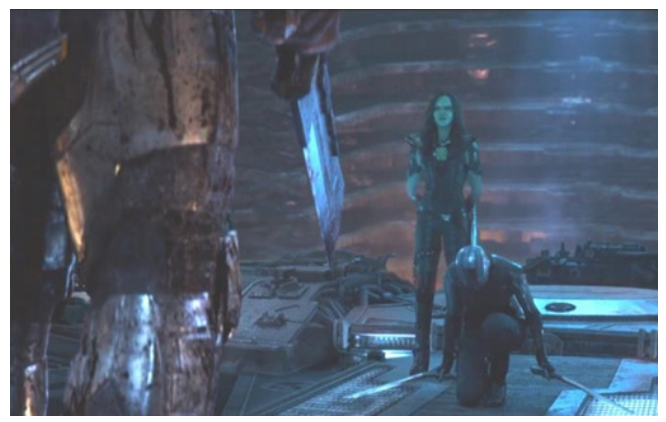

Figure 2 Gamora in dificult condition

For Black Widow, she is "too behaved" like a sister to Hawkeye, especially after Thanos wiped the human population that had included Hawkeye's family. Her character 
undergoes an emotional phase as she monitors Hawkeye's vigilante spree around the world for five years as if she feels somewhat responsible for his family's disappearance. This emotional phase can be seen when Black Widow retrieved Hawkeye in Japan. She told Hawkeye that they had found a solution to reverse Thanos plans, to which Hawkeye replied: "Do not... Do not give me hope." Then she said, "I am sorry that I could not give it to you sooner." It implies that she had been in emotional pain that she could not help him for five years which indicate that she has a nurturing attribute put onto her character.

For Nebula character, similarly to Gamora, she bickers and competes with Gamora like any sister relationship would do; however, her obsession to seek approval and attention from Thanos reassemble as a daughter who wants to be noticed and loved by her father. She obediently follows Thanos's order and shows great courtesy in Thanos's presence despite knowingly that Thanos is a merciless and highly goal-driven warlord.

\section{b. Balance of power}

For the balance of power, it describes the contrast between female and male dominancy through narrative. By massacring Gamora species at a young age and Nebula being adopted into his team of assassins, the two of these characters relied heavily on Thanos as a father figure, which explains their loyalty, respect, and obedience to his instruction, disregard whether they disagree. It even leads to sibling's rivalry between Gamora and Nebula to gain Thanos' attention, and approval is seen as a competition.

Meanwhile, Black Widow can be seen as the only person who takes note, as shown in Figure 3.

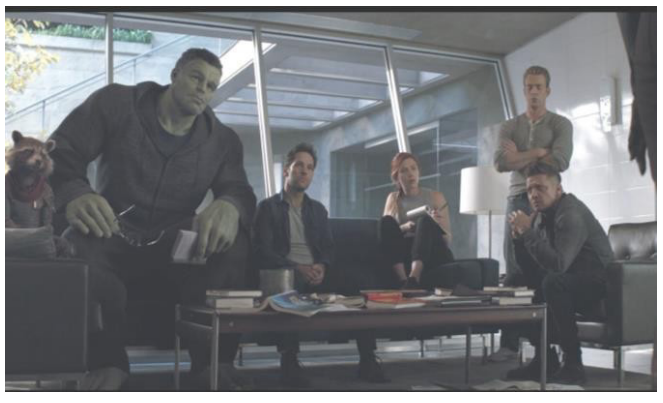

Figure 3 Black Widow and other characters

Another indicator was when they visited Vormir to retrieve the soul stone, which requires a sacrifice for someone they loved the most to be worthy in possession of the stone. Black Widow has sacrificed herself in justification to bring everybody back. However, when Hawkeye challenged her judgement to volunteer for the sacrifice, she then replied:" Do you think that I wanna do it? I am trying to save your life, you idiot." This conversation implicates that she is hesitant and scared to sacrifice herself. However, she values Hawkeyes' life, thus justifying her willingness to sacrifice herself. Here we can see that Black Widows character is to protect and support Hawkeyes' character. Meanwhile, Hawkeye is insistent that it should be him by saying, "Natasha, you know what I have become.", an indication that he is ashamed of his vigilante murder spree for the past five years, hence his justification to sacrifice himself rather than Black Widow, to which she replied, "I do not judge people of their past."

\section{Sexualization Portrayal}

a. Body and outfit representations

Inthissection, thethreefemale characters' bodies will be analyzed and identified on how the female body is portrayed. After observing the film's entirety, the three-female character 
can see a 'standardized' body shape pattern. The three of them possess a similar body type: slender arms, legs, slim waist with body fitted outfits that accentuate their body shape. These findings are related to Sebastian's Work (2019), which states that females are given a 'unique' pose even in posters of superhero films.

However, despite their nature to dwell in the combative situation in this movie, their body shows no muscular profile on their arm and abdomen. The difference in the case for Nebula and Black Widow, they look muscular only when they have their suits on, as shown in screenshot picture of the three-female character in the film Avengers: End Game, as seen in figure 4.

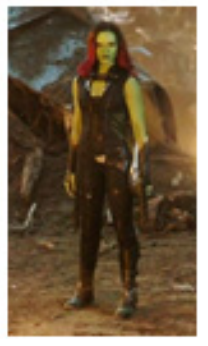

Gamora

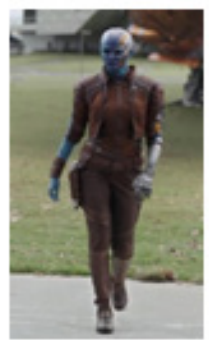

Nebula Black Widow
Figure 4 Women figures with their characteristic

As we first watch the film itself, it does not show any signs of stereotypical female representation. Furthermore, it gives a sense of empowerment as a female watching a female superhero save the world with their male superheroes. Not until watching it several times with added knowledge towards media representations that then identify that female is still being stereotypically represented in The Avengers: End Game.

According to Ito (1994), women are almost always performing traditional, domestic, female roles such as a mother, daughter, niece, grandmother, sister, sister- in-law, widow, kyoiku mama, girlfriend, mistress, and lover, whereby is evident in terms of occupation found in the Avengers: End Game film. The domestic role is still attached to the three-female superheroes character: Gamora, Black Widow, and Nebula, throughout the narrative. Unlike Susan Storm A.K.The Invisible Girl was a mighty superhero in her own right and was relegated to the role of girlfriend, wife, and mother in the end (Dunne, 2006: 6).

Although, in the 2019 Avengers: Endgame film, the three-female superheroes roles were not as girlfriends or a mother who cooks and cleans but was instead emphasized in the film as the role of a sister despite having no blood relation to each other. Somehow, the female role in films has trouble bursting out of the domestic bubble, especially in a film dominated by male characters. D'Amore (2012) stated that the women superhero was placed on a pedestal of achievement, playing with the boys, and developing strength and identity in areas not traditionally available to women. Nevertheless, females in a majority male universe, symbolically they had nowhere to go except into the roles of women that were recognizable and familiar. This symbol leads to the continuation of stereotypical female roles where females are confined in domestic roles, which relate to the next part, the balance of power.

Emad (2006) argued that female comic book characters relied on their male counterparts to rescue them, care for them, make decisions for them, and give them a purpose in life. In this film, the balance of power between male and female are not equally distributed, whereby it is evident that the three-female superheroes decision making lies in the hands of their male counterpart. 
It can be seen between Gamora, Nebula and Thanos' relationship. The sister rivalry to seek Thanos's approval and attention is a way for them to find the sense of validation that they are worthy of their adoptive father. Hence, a female sense of purpose and power has been put in the hands of a male.

Similar goes to Black Widow her entire portrayal throughout the film acted as a support system and their intermediary among male superheroes where she can be seen agreeing and supporting her male counterpart in any discussion or meetings, never were the one who initiated a new idea or opinion, especially in term of big mission such as saving the world. Thus, putting her power below her male counterparts. Another indication of the power imbalance between female and male counterparts is when her power and logic in decision making relied on Hawkeye value.

There is a difference of power between Black Widow and Hawkeyes intention to sacrifice themselves for the soul's stone. Hawkeyes justify his intention by relating his dark past and by sacrificing himself for the benefit of the world that will correct his past. Meanwhile, Black Widow was willing because she wanted to save Hawkeyes' life despite being scared herself. Hawkeyes' intention is self-implicating which has decreased his power over the storyline. However, his character was then given back the power by Black Widow, where she emphasized by saying, "I do not judge people of their past."

Ito (1994) mentioned in her study on Women's Image in Weekly Male Comic Magazine in Japan that in these stories, women are usually depicted at best in an "accessory" role in the plot. If the male characters are compared to football players on the field, the female characters are "cheerleaders" at best. This plot shows how female representation is shown merely to support the male superheroes in achieving their goal. Further, patriarchal ideology can be strengthened where males are dominant, and females are oppressed, perpetuating discrimination, prejudice, and inequality.

In addition, to show that to make them relatable and desirable characters, Gamora and Nebula, a different species than Black Widow, which is human, had their appearance interpreted to possess a human-like body. Moreover, since both Gamora and Nebula are female, their body has been given a feminine shape and accentuated with body fitted suit, with added long wavy hair for Gamora. According to Bordo (2003), being 'feminine' is linked with being slender, not taking up space.

We can see the pattern of body size among these three-female superheroes; it is repeated among them, which sends a message to the loyal audience that this body shape is the "ideal and desirable" body type-some elements fuel media representation, which consists of repeated elements. The more we see these elements repeated, the more the representation will appear to be natural or normal (Stewart \& Kowaltzke, 1997). This type of body representation is dangerous and can cause abuse in how female audiences see their bodies, such as developing eating disorders and depression because not everyone interprets the media the same approach. Furthermore, they explain that media representation works because it invites audiences to understand them and agree with them in specific preferred ways. However, depending on the audience, different interpretations are, to some extent, possible.

The stereotype of female representation 
does not limit itself in comic books; however, it can be reproduced into another means of mass audience platform, in this case, films. Female representation in media has gone through many changes throughout history. It has been mimicked, framed and produced following the life situation of that period. During the PostWar, female representation was stereotyped and was quickly identified. As the feminism movement rises, these stereotypes of female representation have improved through readjusting and reconstructing.

However, with constant eye-watched by the critical feminist viewer, stereotypes can hide behind the narrative. Thus, to some, Marvel's film may be an empowering platform for female representation. However, in terms of gender role and sexualization or physical appearance, somehow female representation cannot go beyond far from familiarity, which in this case, taking domestic roles and conforming to unhealthy and even unrealistic body image.

Finding in this study has a similar argument with the one conducted by Arofat (2013) related women representation in nuanced Islamic movies. The finding in Arofat's study shows that that the construction of the female role in the nuanced Islamic film is related to the domestic role, as mother or wife with domestic tasks. Arafat furthermore explained that female identity construction in the movie has emotional engagement with male existence.

If we look at this issue from a diverse perspective, the Islamic perspective, as in Muhibbin's work (2011), it is stated that Islam never has distinguished males and females based on their gender role and status. Furthermore, he stated that from the perspective of sharia, Islam sharia had established the principle of emancipation both theoretically and operational. Thus, it is essential to highlight the critical thought of that representation of female character and role in the media, especially film in this context, has to be relooked and reconstructed to avoid the similar stereotypical all over again in every production. Although being a mother or any domestic role is not entirely attached to the harmful notion, when it has limited female ability to expand beyond their gender and create an unequal representation of females compared to males, it causes issues such as gender discrimination, prejudice and inequality.

\section{Conclusion}

The analysis has shown that (i) each of the characters plays several roles based on the context of the story, (ii) the balance of power between male and female are not equally distributed, and lastly, Gamora and Nebula being a different species than Black Widow which is human, had their appearance interpreted to possess a human-like body, yet the pattern of body size among these three-female superheroes, it is repeated among them which sends a message to a loyal audience that this body shape is the "ideal and desirable" body type.

The present study's findings provided newinsightsinto analyzing therepresentations of female characters in superhero films and provide new ways of conducting such analysis for the academic community interested in exploring media representations, be it in advertising, television, or films. The use of Roland Barthes Semiotics has helped this study explore the representations in this study into the next level, the second-order 
whereby connotative and further critical comparison can be considered.

Furthermore, a new perspective on the content displayed by any media provides the senses of awareness and mindfulness in digesting the elements in media content. Especially in terms of gender stereotypes representation, people of colour, religion, body image, and differently able people, which in this case, how females are being represented in popular convergence form of medium such as comic books to films. Moreover, addressing individuals interested in filmmaking, this study can be valuable to refer to and could benefit from conducting a similar study regarding representations in film from various perspectives.

\section{References}

Alzahrani, F. (2016). The Portrayal of Women and Gender Roles in Films. International Journal of Scientific \& Engineering Research, Vol. 7 (4), 533-534.

Arofat, S. (2013). Representasi Perempuan dalam Film Bernuansa Islami. Refleksi, Vol. 13(4), 495-528.

Baran, S. J. (2014). Introduction to Mass Communication: Media Literacy \& Culture. Boston: McGraw-Hill Education.

Basarah, F. F. (2019). Feminisme dalam Web Series "Sore-Istri dari Masa Depan" (Analisis Wacana Sara Millis). Widyakala Journal, Vol. 6 (2), 110-120.

Blackston, A. M. (2003). Gender Role \& Society. Miller, J. R., Lerner, R. M., \& Schiamberg, L. B. (Eds.) Human Ecology: An Encyclopedia of Children, Families, Communities, and Environments, 335338. Santa Barbara, CA: ABC-CLIO.
Bordo, S. (2003). Unbearable Weight: Feminism, Western Culture, and the Body (tenth anniversary edition). Berkeley, CA: University of California Press.

Bouzida, F. (2014). The Semiology Analysis in Media Studies: Roland Barthes Approach. Proceedings of SOCIOINT4International Conference on Social Sciences and Humanities, 1001-1007.

Briandana, R. \& Hajariah, S. (2013). Gender and the Action Film: Question of Female Heroism (Analysis of Female Masculinity of the Female Heroic Character). Jurnal Visi Komunikasi, Vol. 12 (2), 183-198.

Butler, J. (1990). Gender Trouble: Feminism and the Subversion of Identity. Great Britain: Routledge, Chapman \& Hall.

D'Amore, L. M. (2012). The Accidental Supermom: Superheroines and Maternal Performativity, 1963-1980. The Journal of Popular Culture, Vol. 45(6), 12261248.

Danesi, M. (2004). Pesan, Tanda dan Makna. (Setyarini, A. \& Piantari, L. L, Trans.). Yogyakarta: Jalasutra

Dunne, M. (2006). The representation of women in comic books, post WWII through the radical 60s. PSU McNair Scholars Online Journal, Vol. 2(1), Article 20.

Eriyanto. (2001). Analisis Wacana: Pengantar Analisis Teks Media. Yogyakarta: LKIS.

Emad, M. C. (2006). Reading Wonder Woman's body: Mythologies of gender and nation. Journal of Popular Culture 39(6), 954984.

Gablaski, J. (2020). Super or Sexist? The Evolution of Female Superheroes in Comics in Film. Honors Theses. 84. 
https://digitalcommons.assumption. edu/honorstheses/84

Gerard, M. (2018). Black Widow: Female Representation in the Marvel Cinematic Universe. Polymath: An Interdisciplinary Arts and Sciences Journal, pp. 27-53.

Hall, S. (2009). Representation: Cultural Representation \& Signifying Practices (p. 15). California, US: Sage Publication.

Ito, K. (1994). Image Of Women in Weekly Male Comic Magazine in Japan. The Journal of Popular Culture, Vol. 27(4), 81-95.

Krahn, K. M. (2015). Reel Women: Gender Stereotypes in Films. Master's Theses, and Doctoral Dissertations, and Graduate Capstone Projects, Eastern Michigan University.

Kunsey, I. (2018). Representations of Women in Popular Film: A Study of Gender Inequality in 2018. Elon Journal of Undergraduate Research in Communications, Vol. 10(2), 27-38.

Lester, P. M., \& Ross, S. D. (2003). Images that injure: Pictorial stereotypes in the media. Westport, Conn: Praeger.

Majhi, G. 2017. Paradox of Gender Equality in Hollywood Superhero Movies. Arts \& Education International Research Journal, Vol. 4(2), 5-9.

Misiroglu, G., Sanderson,. Peter and Eury,. Michael (2017, February 1). Superhero. Encyclopedia Britannica. https://www. britannica.com/art/superhero

Muhibbin, Z. (2011). Wanita dalam Islam. Jurnal Sosial Humaniora, Vol. 4(2), 109120.

Murphy, J. N. (2015). The role of women in film: Supporting the men -An analysis of how culture influences the changing discourse on gender representations in film. Journalism Undergraduate Honors Theses.

Murphy, K. (2016). Analyzing Female Gender Roles in Marvel Comics from the Silver Age (1960) to the Present. Discussion: The Undergraduate Research Journal of CWRU, 8-17.

Pickering, M. (2016). Stereotyping and Stereotypes. In R. P. JohnStone, The Wiley Blackwell Encyclopedia of Race, Ethnicity, and Nationalism, (First Edition). John Wiley \& Sons, Ltd.

Scheiner-Fisher, C. (2013). The Inclusion Of Women's History In The Secondary Social Studies Classroom. Electronic Theses and Dissertations, 2004 - 2009. University of Central Florida.

Sebastian, R. (2019). Women and Action: The Representation of Hollywood Superhuman Film Wonder Woman. https: / / www.researchgate.net/ publication/343627491_Women_ and_Action_The_Representation_of_ Hollywood_Superhuman_Film_Wonder_ Woman

Stewart, C \& Kowaltzke, A. (1997). Media New Ways and Meanings. Milton, Qld: John Wiley \& Sons Australia.

Thaller, S. (2016). A Feminist Bait-AndSwitch: The Hunger Games And The Illusion Of Empowerment. A Journal of Literary Criticism and Analysis. https:// www.ohio.edu/cas/parlour/news / hunger-games-illusion-empowerment

Timetoast. Gender Bias in Advertisements Over Time https://www.timetoast. com/timelines/gender-bias - ofadvertising-1920 Retrieved in 20 
February 2021.

Toni, A. (2019). Wacana Kepemimpinan Perempuan Dalam Film 'Opera Jawa' Karya Garin Nugroho. KOMUNIKA: Jurnal Dakwah Dan Komunikasi, 13(2). https:// doi.org/https://doi.org/10.24090/ komunika.v13i2.2072

Turberville, T. (2016). The Female Justice League: The Misrepresentations of Women n Comic Books. Stylus Knights Write Showcase Special Issue, 71-82.
Wibowo, I. S. W. (2011). Semiotika Komnikasi Aplikasi Praktis Bagi Penelitian dan Skripsi Komunikasi. Jakarta: Mitra Wacan Media.

Zurbriggen, E. L., Collins, R. L., \& Lamb, S. (2007). Report of the APA Task Force on the Sexualization of Girls. Washington: American Psychological Association. Portland State University (PSU) McNair Scholars Online Journal 20(1), 81-91. 